\title{
PHOTOGRAMMETRY-DERIVED ORTHOIMAGERY AND ELEVATION FOR ALAKANUK, ALASKA, COLLECTED JULY 11, 2021
}

Richard M. Buzard, Jessica E. Christian, and Jacquelyn R. Overbeck

Raw Data File 2021-17
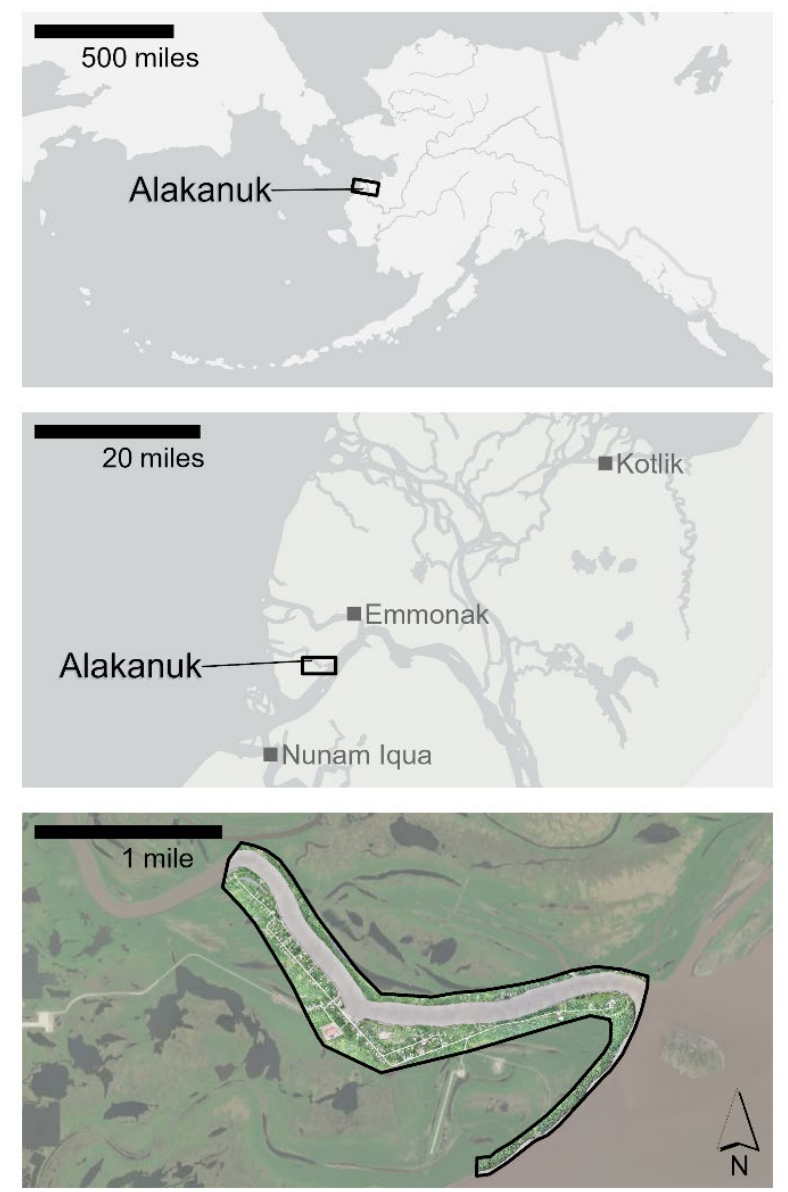

Location map of survey area with orthoimage.

This report has not been reviewed for technical content or for conformity to the editorial standards of DGGS.

2021

STATE OF ALASKA

DEPARTMENT OF NATURAL RESOURCES

DIVISION OF GEOLOGICAL \& GEOPHYSICAL SURVEYS
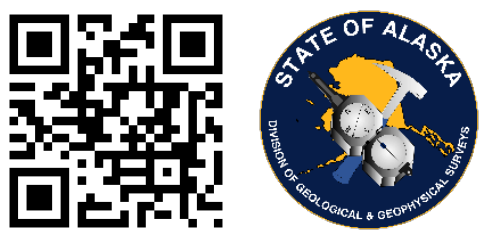


\section{STATE OF ALASKA}

Mike Dunleavy, Governor

\section{DEPARTMENT OF NATURAL RESOURCES}

Corri A. Feige, Commissioner

\section{DIVISION OF GEOLOGICAL \& GEOPHYSICAL SURVEYS}

Steve Masterman, State Geologist \& Director

Publications produced by the Division of Geological \& Geophysical Surveys are available to download from the DGGS website (dggs.alaska.gov). Publications on hard-copy or digital media can be examined or purchased in the Fairbanks office:

\section{Alaska Division of Geological \& Geophysical Surveys (DGGS)}

3354 College Road | Fairbanks, Alaska 99709-3707

Phone: 907.451 .5010 | Fax 907.451.5050

dggspubs@alaska.gov | dggs.alaska.gov

DGGS publications are also available at:

Alaska State Library, Historical

Collections \& Talking Book Center

395 Whittier Street

Juneau, Alaska 99801

Alaska Resource Library and

Information Services (ARLIS)

3150 C Street, Suite 100

Anchorage, Alaska 99503

\section{Suggested citation:}

Buzard, R.M., Christian, J.E., and Overbeck, J.R., 2021,

Photogrammetry-derived orthoimagery and elevation for

Alakanuk, Alaska, collected July 11, 2021: Alaska Division of

Geological \& Geophysical Surveys Raw Data File 2021-17, 4 p.

https://doi.org/10.14509/30790

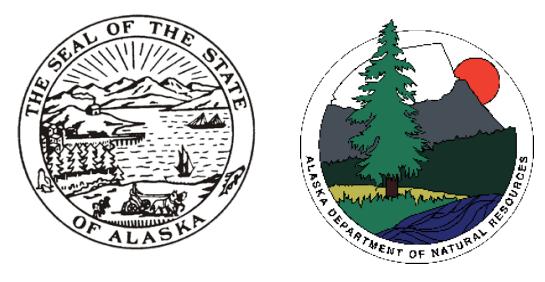




\title{
PHOTOGRAMMETRY-DERIVED ORTHOIMAGERY AND ELEVATION FOR ALAKANUK, ALASKA, COLLECTED JULY 11, 2021
}

\author{
Richard M. Buzard ${ }^{1}$, Jessica E. Christian², and Jacquelyn R. Overbeck ${ }^{1}$ \\ INTRODUCTION
}

The State of Alaska Division of Geological \& Geophysical Surveys (DGGS) collected low-altitude aerial images from an unmanned aerial vehicle (UAV) on July 11, 2021 and used Structure-from-Motion (SfM) photogrammetry to produce a digital surface model (DSM) and orthoimage of Alakanuk. The orthoimage and elevation data are for assessing coastal hazards and changes. We used Trimble Business Center to process the Global Navigation Satellite System (GNSS) data used for positional control. We used Agisoft Metashape to process the photogrammetry data. These products are released as a Raw Data File with an open end-user license. All files can be downloaded from doi.org/10.14509/30790 or elevation.alaska.gov.

\section{LIST OF DELIVERABLES}

- Orthoimage

- Digital Surface Model (DSM)

- Metadata
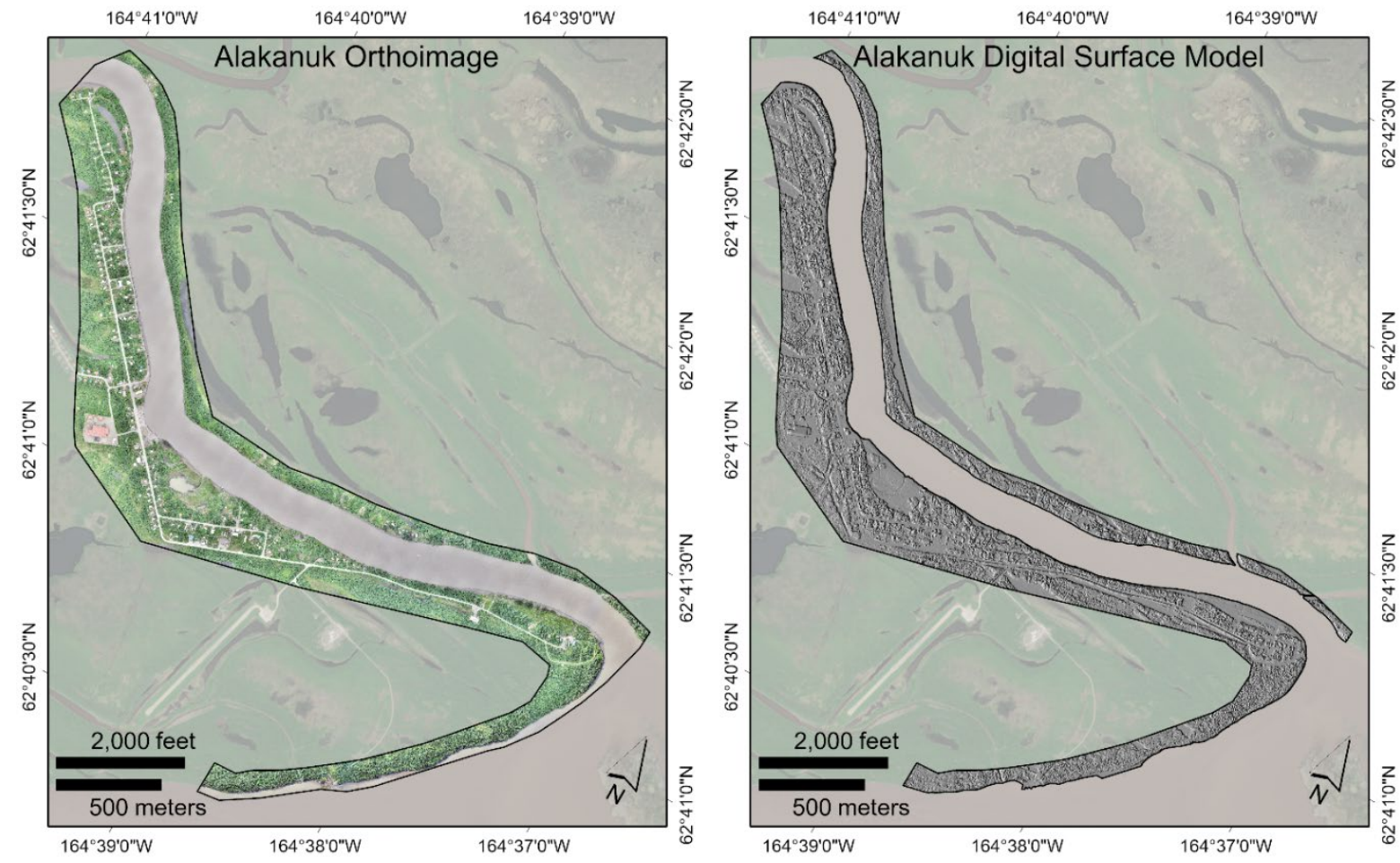

Figure 1. Extent of orthoimage (left) and DSM (right) for Alakanuk.

\footnotetext{
${ }^{1}$ Alaska Division of Geological \& Geophysical Surveys, 3354 College Road, Fairbanks, AK 99709.

2 University of Alaska Fairbanks Arctic Coastal Geoscience Lab, P.O. Box 755780, Fairbanks, AK 99775
} 


\section{MISSION PLAN}

\section{Aerial Photogrammetric Survey Details}

DGGS used a DJI Phantom 4 RTK UAV with a FC6310R camera model (8.8 mm lens) to collect 20 -megapixel JPEG photographs ( $5472 \times 3648$ pixels per image). We flew the aerial survey with 70 percent sidelap and 80 percent frontlap, $120 \mathrm{~m}$ above the ground at $7.9 \mathrm{~m} / \mathrm{s}$, with nadir camera orientation stabilized by a 3-axis gimbal. The resulting images cover 2.42 $\mathrm{km}^{2}$ with ground sampling distance (GSD) of approximately $0.03 \mathrm{~m}$.

\section{Weather and Photo Conditions}

DGGS conducted flights on July 11, 2021, from 5:30 to 8:45 PM AKDT. The operator returned the UAV eight times to change batteries. The weather was favorable with overcast clouds, no rain, and light wind. No abnormalities were observed during the flights.

\section{SURVEY AND PROCESSING REPORT}

\section{Ground Survey Details}

DGGS set up a GNSS base station using a Trimble R10 receiver sampling at $5 \mathrm{~Hz}$. The base was installed over a temporary benchmark of unknown position. This provided real-time kinematic (RTK) corrections to the UAV and Trimble R8s GNSS receiver. DGGS measured 21 photo-identifiable points with the R8s. We derived the corrected base position using the Online Positioning User Service (found at www.ngs.noaa.gov/OPUS/) and post-processed the R8s positions in Trimble Business Center.

\section{Photogrammetric Dataset Processing}

The UAV maintained RTK connection throughout the survey. The RTK system automatically applies the lever arm correction when writing camera GNSS coordinates (WGS84 ellipsoid) to the image metadata. Yaw, pitch, and roll information were not written to the image metadata. We update UAV positions using a X, Y, and Z shift from the initial to the corrected base position.

DGGS processed images in Agisoft Metashape Professional software (Version 1.6.3 build 10732). We masked image corners where shadows and image warping were disruptive. Processing steps included aligning images, identifying ground control points (GCPs), manually cleaning the sparse point cloud, optimizing the bundle block adjustment (refining camera positions and lens distortion parameters), constructing the dense point cloud, building the DSM, and creating the orthomosaic image. We used five GCPs to create the model, leaving sixteen survey check points.

\section{Orthoimagery}

The orthoimage is a three-band (red, green, blue) 8-bit unsigned GeoTIFF file with a GSD of $0.034 \mathrm{~m}$ per pixel, the "No Data" value is set to 0 .

\section{Digital Surface Model}

The DSM represents surface elevations such as the height of vegetation and buildings. Water bodies can introduce noise. We manually delineated the river boundaries to restrict the DSM to the land. The DSM is a single-band, 32-bit floating point GeoTIFF file with a GSD of $0.068 \mathrm{~m}$, the "No Data" value is set to $-3.4028231 \times 10^{38}$. 


\section{ACCURACY REPORT}

\section{Coordinate System and Datum}

All data are processed and delivered in NAD83 (2011) UTM Zone 3N and vertical datum NAVD88 (GEOID12B).

\section{Horizontal Accuracy}

We quantify the horizontal accuracy of the DSM and orthoimage by comparing the known locations of 16 photo-identifiable check points measured with GNSS against their modeled locations in the photogrammetric products (fig. 2). X and Y errors are calculated as the root-mean-square (RMS) error of offsets. The total horizontal error is the root-sumsquare error of X and Y RMS errors, $0.048 \mathrm{~m}$ (table 1).

\section{Vertical Accuracy}

We assess the vertical accuracy of the DSM using the same check points. The RMS error of Z offsets is $0.041 \mathrm{~m}$ (table 1). The total error of the DSM (X, Y, and Z) is $0.063 \mathrm{~m}$.

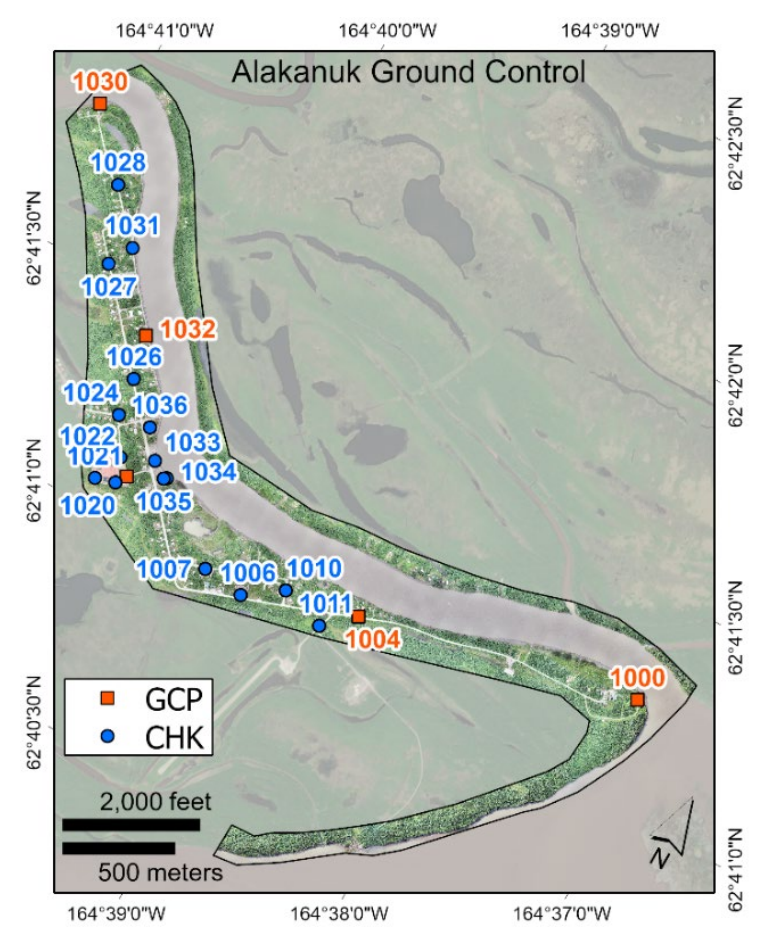

Figure 2. Location of photo-identifiable ground control points (GCPs; red) and check points (CHK; blue). 
Table 1. Check point coordinates and offsets from orthoimage and DSM.

\begin{tabular}{|c|c|c|c|c|c|c|}
\hline Check Point & Easting & Northing & Elevation & X Offset (m) & Y Offset (m) & Z Offset (m) \\
\hline 1006 & 517720.826 & 6950350.620 & 4.240 & -0.040 & -0.038 & 0.028 \\
\hline 1007 & 517527.339 & 6950372.858 & 4.342 & -0.024 & 0.029 & 0.061 \\
\hline 1010 & 517882.874 & 6950467.831 & 5.054 & -0.035 & -0.047 & 0.035 \\
\hline 1011 & 518089.041 & 6950406.298 & 4.079 & 0.041 & 0.083 & 0.056 \\
\hline 1020 & 516994.505 & 6950505.649 & 4.735 & -0.010 & -0.008 & -0.017 \\
\hline 1021 & 516905.491 & 6950476.694 & 4.412 & 0.037 & -0.005 & -0.024 \\
\hline 1022 & 516958.313 & 6950611.627 & 4.672 & 0.017 & -0.022 & -0.011 \\
\hline 1024 & 516857.455 & 6950770.234 & 4.084 & -0.008 & 0.000 & -0.045 \\
\hline 1026 & 516836.229 & 6950940.622 & 4.218 & -0.019 & 0.008 & -0.039 \\
\hline 1027 & 516485.543 & 6951325.417 & 4.212 & -0.072 & 0.057 & -0.043 \\
\hline 1028 & 516346.823 & 6951648.546 & 3.617 & 0.001 & 0.055 & -0.088 \\
\hline 1031 & 516542.290 & 6951439.275 & 3.908 & -0.005 & -0.011 & 0.012 \\
\hline 1033 & 517097.334 & 6950675.765 & 4.019 & 0.022 & -0.062 & 0.035 \\
\hline 1034 & 517180.438 & 6950634.212 & 3.928 & -0.004 & -0.008 & 0.039 \\
\hline 1035 & 517169.077 & 6950625.553 & 3.957 & -0.032 & 0.011 & 0.035 \\
\hline \multirow[t]{6}{*}{1036} & 517004.842 & 6950791.695 & 3.941 & 0.001 & 0.008 & 0.000 \\
\hline & & & Mean & -0.008 & 0.003 & 0.002 \\
\hline & & & Standard Deviation & 0.029 & 0.039 & 0.042 \\
\hline & & & Range & 0.113 & 0.145 & 0.149 \\
\hline & & & Root Mean Square Error & 0.030 & 0.038 & 0.041 \\
\hline & & & Total Error & \multicolumn{2}{|c|}{$0.048(X Y)$} & $0.063(\mathrm{XYZ})$ \\
\hline
\end{tabular}

\section{Data Consistency and Completeness}

DGGS visually inspected the orthoimage for data errors such as shifts, seamline mismatches, and water noise overlapping land. There were no significantly erroneous areas that required repair. Visual errors common to these SfM photogrammetry products include discontinuous powerlines, blurriness near high-angle features like buildings, and distortion at water boundaries. Bright objects like metal roofs and white paint can cause overexposure, leading to spurious elevation points.

\section{ACKNOWLEDGEMENTS}

We thank the Alakanuk Village for funding and supporting the creation of these data products. 